\title{
Refinery Production Planning: Multiperiod MINLP with Nonlinear CDU Model
}

Abdulrahman M. Alattas ${ }^{1}$, Ignacio E. Grossmann ${ }^{1 *}$, Ignasi Palou-Rivera ${ }^{2}$

${ }^{1}$ Chemical Engineering Department, Carnegie Mellon University, Pittsburgh, PA 15213, USA

${ }^{2}$ Lanza Tech, Roselle, IL 60172

\section{Abstract}

In a previous paper, Alattas, Grossmann \& Palou-Rivera (2011) developed a single-period, nonlinear programing refinery planning model using the fractionation index (FI) for the crude distillation unit (CDU) equations. In this paper, the single period model is modified to a mixed-integer nonlinear programming (MINLP) model to determine the sequencing, changeovers and processing times of crude oils over multiple time periods. The MINLP equations include traveling salesman problem constraints to generate the crude oil sequences that maximize profit. Moreover, the disjunction for the fractionation index (FI) is formulated with mixed integer constraints as opposed to the Heaviside function formulation of the previous work. The resulting model is shown to be robust and relatively fast. When subcycles arise, they are eliminated by adding appropriate subtour elimination constraints. Examples with up to 5 crude oils and 6 weeks time horizon are presented to illustrate the application of the proposed model. 


\section{Introduction}

Production Planning is an essential tool in today's petroleum refining industry. It aids in decision making and resource allocation to achieve business objectives through optimal production, distribution, sales and inventory management ${ }^{1,2}$. The refinery planning models differ in their levels of model complexity and sizes. They span the strategic level of single period, long term, crude-selection planning model to the operational multi-period, short term, crudeallocation-and-movement operation planning model ${ }^{3,4,5}$. The refining industry is one of the early adaptors of linear programming (LP) to address its planning and optimization needs ${ }^{6}$. The LP approach simplifies the inherent nonlinearity of the refinery processes to ensure simplicity, robustness and convenience of the models at the expense of true optimal and accurate solutions to the planning model. The need for more accurate nonlinear representations of the process units as well as integrated planning and scheduling refinery operation models are recognized as key future challenges in the field ${ }^{5,7,8,9}$. Multiperiod refinery planning models tend to utilize linear equations for the process units ${ }^{10,11,12}$. The nonlinear implementation for the process unit in multiperiod planning models rely mainly on empirical relations ${ }^{13}$.

In our previous work ${ }^{14}$, we presented the fractionation index (FI) model as a nonlinear model for the crude distillation unit (CDU), the front end of the refinery and an important process unit. The model benefited from the simple and crudeindependent equations generated using the column-characteristic FI values and gave a more accurate and relatively fast model. The model was successfully integrated into a single period time horizon planning model for crude purchase decision. The natural next development for the robust nonlinear FI model is to integrate the scheduling element for an improved refinery-wide optimization. In this paper we extend the FI model to multiperiod implementation as a step toward a comprehensive planning and scheduling model. Our multiperiod model uses continuous time representation ${ }^{15,16}$ addressing a planning and scheduling problem for continuous multiproduct plants. The approach used is to develop an accurate upper level planning incorporating changeovers, product inventories and periodic product demands, using the traveling salesman constraints to generate the processing sequence.

\section{Problem Statement}

Given is a configuration of the refinery whose operation is to be optimized over several time periods. The configuration, similar to the one shown in Figure $1{ }^{17}$, provides information on the major separation, conversion and blending units, along with the refinery feed streams, product streams and interconnections between the different units. Refineries differ in the number or types of process units they have depending on the quality of crude oils they process and the product slates. In this paper, the configuration of Figure 1 is used, where the 
crude is separated into different cuts in the crude distillation unit (CDU). Each cut is sent to a different conversion or treatment unit (reformer, catalytic cracking or hydrotreatment units) or to product blending.

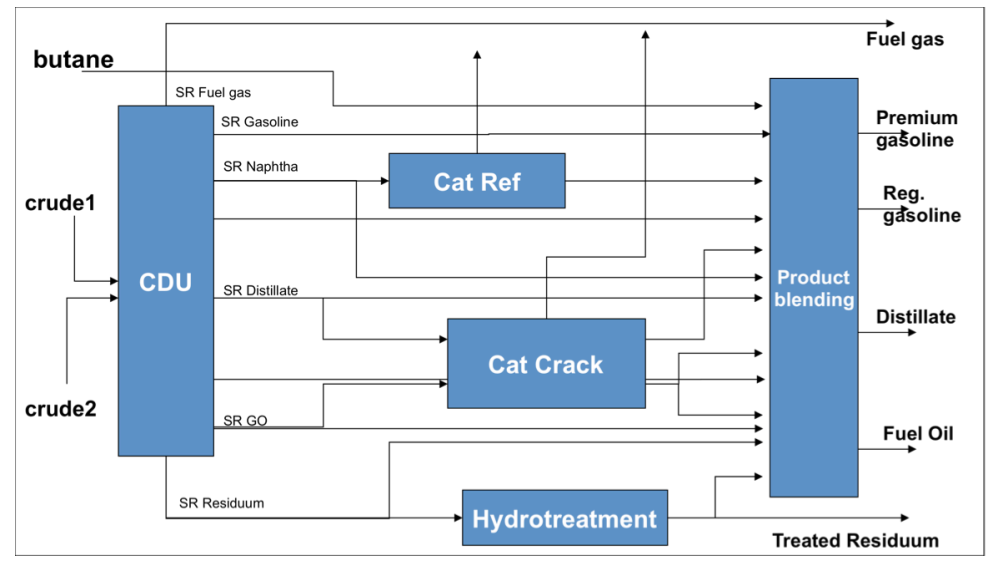

Figure 1 Complex Refinery Configuration

In addition to the configuration, the following information is assumed to be given

- Crude oils. The availability of crude oils are specified, along with their properties and compositions, typically in the form of the crude assays. Several processing parameters, property values and indices are generated.

- Refinery units. There is information on the capacities of these units and minimum feed requirements. The required coefficients for yield and property calculations are generated from the units and crude oil information,

- Product slates. The list of the products produced by the refinery and their possible constituting streams are given. The required product qualities are also specified, along with minimum or maximum demands. The demands are specified at the end of each time period.

- Product inventory. In this work, we consider only the final product storage. The cost of storing these products is specified along with any initial inventory at the start of period 1 .

- Changeovers. Due to the variation in crude qualities, changeovers are sequence dependent. The changeovers are specified in terms of duration and cost.

- Planning horizon. The horizon and the period duration are also specified. We consider 4 to 6 weeks time horizon, with 1 week time periods.

Based on the above information, the objective is to determine the operation that maximizes profit (or equivalently minimizes cost) in terms of the following decisions:

- What crude oil to process and in which time period

- The quantities of these crude oils to process

- The sequence of processing them 
- The rate of processing those crude oils and the processing duration

- The refinery products produced, their quantities and storage requirement

\section{Mathematical Formulation}

The mathematical formulation for the multiperiod refinery planning model builds on the previous work of Alattas, Grossmann \& Palou-Rivera (2011) ${ }^{14}$ and Erdirik-Dogan \& Grossmann (2008) ${ }^{16}$. The formulation can be broken into three layers. The inner layer is the fractionation index model (FI) which is the nonlinear CDU model. The middle layer is the refinery planning model, which in this work is a linear model. The last layer is the multiperiod extension, which is an MINLP model.

In contrast to the single period model ${ }^{14}$, the FI and planning model equations include additional indices for the processed crude $\mathrm{cr}$ at time period $t$.

\subsection{Fl Model}

The FI model is based on the fractionation index introduced by Geddes ${ }^{18}$. It allows calculating the yield and cut point temperature of the CDU cuts using the column-characteristic FI values. The FI model represents the CDU as a series of fractionation unit, as shown in Figure 2.

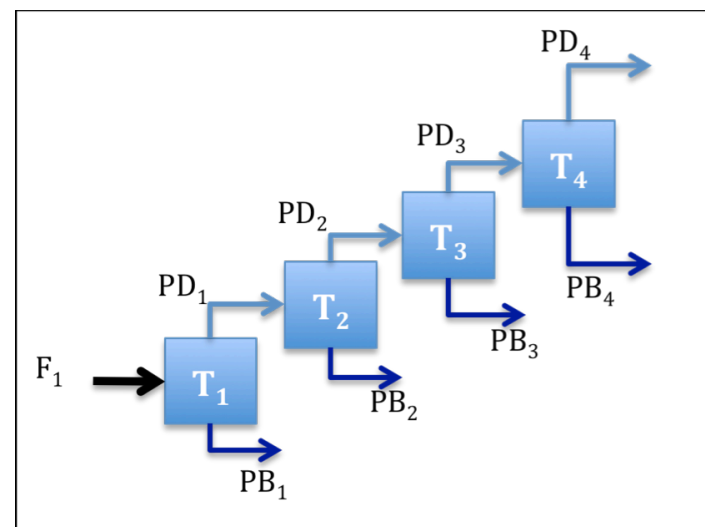

Figure 2 CDU Representation for the FI Model

The NLP model for the CDU starts with a mass balance around each unit $j$ and component $i$. Every unit yields the top product $P D_{j, i, c, t}$ feeding the next unit and the bottom product $P B_{j, i, c r, t}$, which is the product crude cut. There is also a summation equation for each type of stream over its set of constituent components i's

$$
\begin{array}{ll}
F_{j, i, c r, t}=P D_{j, \text { total }, c r, t} x_{P D, j, i, c r, t}+P B_{j, t o t a l, c r, t} x_{P B, j, i, c r, t} & \forall j, i, c r, t \\
F_{j+1, i, c r, t}=P D_{j, t o t a l, c r, t} x_{P D, j, i, c r, t} & \forall j, i, c r, t \\
P B_{j, i, c r, t}=P B_{j, t o t a l, c r, t} x_{P B, j, i, c r, t} & \forall j, i, c r, t
\end{array}
$$




$$
\begin{array}{ll}
P D_{j, i, c r, t}=P D_{j, t o t a l, c r, t} x_{P D, j, i, c r, t} & \forall j, i, c r, t \\
F_{j, t o t a l, c r, t}=\sum_{i} F_{j, i, c r, t} & \forall j, i, c r, t \\
P D_{j, t o t a l, c r, t}=\sum_{i} P D_{j, i, c r, t} & \forall j, i, c r, t \\
P B_{j, t o t a l, c r, t}=\sum_{i} P B_{j, i, c r, t} & \forall j, i, c r, t
\end{array}
$$

The component distribution at each stage $j$ is based on the light key $L K_{j}$ and heavy key $H K_{j}$ components for each unit based on the initial and end boiling points relative to each cut. The components lighter than the light key are only obtained in the top product stream, while the ones heavier than the heavy key are only obtained in the bottom product stream.

$$
\begin{array}{lll}
P D_{j, i, c r, t}=F_{j, i, c r, t}, P B_{j, i, c r, t}=0 & \forall j, c r, t, i<L K_{j} \\
P B_{j, i, c r, t}=F_{j, i, c r, t}, P D_{j, i, c r, t}=0 & \forall j, c r, t, i>H K_{j}
\end{array}
$$

The splits of the distributed components are calculated using the FI parameters. For each unit, there are two FI values, one for the rectifying section and another for the stripping section. Choice of the correct value is based on the calculated temperature and the particular component. The rectifying $\mathrm{FI}\left(\mathrm{FI}_{\mathrm{r}}\right)$ is used if the temperature is greater than the component boiling temperature; otherwise, the stripping $\mathrm{FI}\left(\mathrm{FI}_{s}\right)$ is used. The following disjunction represents the FI choice,

$$
\left[\begin{array}{c}
\neg Y_{i, j, c r, t} \\
\gamma_{i, j, c r, t}=F I r_{j} \\
T_{b, i} \leq T_{j, c r, t}
\end{array}\right] \bigvee\left[\begin{array}{c}
Y_{i, j, c r, t} \\
\gamma_{i, j, c r, t}=F I s_{j} \\
T_{b, i} \geq T_{j, c r, t}
\end{array}\right] \quad \forall j, i, c r, t
$$

where $Y_{i, j, c r, t}$ is the Boolean (binary) decision variable, $\gamma_{i, j, c r, t}$ is a placeholder for the FI value, $T_{b, i}$ is the component boiling point and $T_{j, c r, t}$ is the cut point temperature.

In our previous work ${ }^{14}$, the Heaviside function was used for this disjunction, yielding the following FI equation for the distributed components,

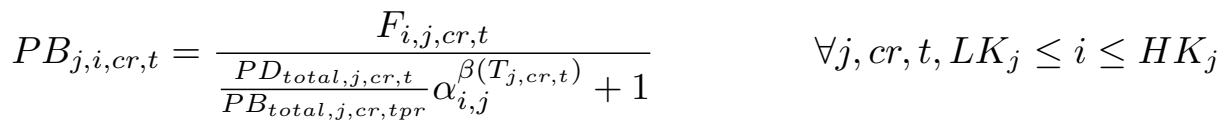

or the simplified form substituting the equilibrium constant for the relative volatility ${ }^{19}$,

$$
P B_{j, i, c r, t}=\frac{F_{i, j, c r, t}}{\frac{P D_{t o t a l, j, c r, t}, \beta}{P B_{t o t a l}, j, c r, t p r} K_{i, j}^{\beta\left(T_{j, c r, t}\right)}+1} \quad \forall j, c r, t, L K_{j} \leq i \leq H K_{j}
$$

where 
$\beta\left(T_{j, c r, t}\right)=\frac{F I r_{j}}{1+e^{4\left(T_{b, i}-T_{j, c r, t}\right)}}+\frac{F I s_{j}}{1+e^{-4\left(T_{b, i}-T_{j, c r, t}\right)}} \quad \forall j, c r, t, L K_{j} \leq i \leq H K_{j}$

As opposed to our previous planning model above, the model presented in this paper corresponds to an MINLP. Therefore, we consider exact representation of the disjunction (10) with linear mixed integer constraints using convex hull as in (14) and big $\mathrm{M}$ formulation as in (15) and $(16)^{20}$,

$$
\begin{array}{ll}
\gamma_{i, j, c r, t}=F I r_{j} *\left(1-Y_{i, j, c r, t}\right)+F I s_{j} * Y_{i, j, c r, t} & \forall j, c r, t, L K_{j} \leq i \leq H K_{j} \\
T_{b, i}+M_{L} * Y_{i, j, c r, t} \leq T_{j, c r, t} & \forall j, c r, t, L K_{j} \leq i \leq H K_{j} \\
T_{j, c r, t} \leq T_{b, i}+M_{U} *\left(1-* Y_{i, j, c r, t}\right) & \forall j, c r, t, L K_{j} \leq i \leq H K_{j}
\end{array}
$$

Notice that at $\mathrm{Y}_{\mathrm{i}, \mathrm{j}, \mathrm{cr}, \mathrm{t}}=0$ (false) that $\gamma_{\mathrm{i}, \mathrm{j}, \mathrm{cr}, \mathrm{t}}=\mathrm{FI}_{\mathrm{r}, \mathrm{j}}$ and $\mathrm{Tb}_{\mathrm{i}} \leq \mathrm{T}_{\mathrm{j}, \mathrm{cr}, \mathrm{t}}$ while at $\mathrm{Y}_{\mathrm{i}, \mathrm{j}, \mathrm{cr}, \mathrm{t}}=1$ (true) that $\gamma_{i, j, c r, t}=F_{s, j}$ and $\mathrm{Tb}_{\mathrm{i}} \geq \mathrm{T}_{\mathrm{j}, \mathrm{cr}, \mathrm{t}}$. Since the components are listed in the order of increasing boiling point, the following constraint is included

$$
Y_{i, j, c r, t} \leq Y_{i+1, j, c r, t} \quad \forall j, c r, t, L K_{j} \leq i \leq H K_{j}
$$

The FI equations (the original and the simplified forms) become,

$$
P B_{j, i, c r, t}=\frac{F_{i, j, c r, t}}{\frac{P D_{t o t a l, j, c r, t}}{P B_{t o t a l, j, c r, t}} \alpha_{i, j, c r, t, t}^{\gamma_{i, j}+1}+1} \quad \forall j, c r, t, L K_{j} \leq i \leq H K_{j}
$$

and

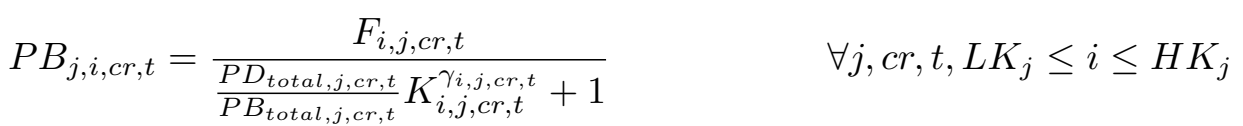

Equations (14)- (19) are an improvement from the original FI model. We examine the impact of this improvement later in the discussion section.

The equilibrium constant and vapor pressure are calculated as follows ${ }^{14}$,

$$
\begin{array}{ll}
K_{j, i, c r, t}=\frac{P v_{j, i, c r, t}\left(T_{j, c r, t}\right)}{P} & \forall j, i, c r, t \\
P v_{j, i, c r, t}=\operatorname{Exp}\left(\left(P V A_{i}-\frac{P V B_{i}}{T_{j, c r, t}+P V C_{i}-273.15}\right) * 2.303\right) & \forall j, i \in H C, c r, t
\end{array}
$$

$P v_{j, i, c r, t}=P c_{i} * \operatorname{Exp}\left(\left[-5.96346 *\left(1-T r_{j, i, c r, t}\right)+1.17639 *\left(1-T r_{j, i, c r, t}\right)^{1.5}\right.\right.$

$\left.-0.559607 *\left(1-\operatorname{Tr}_{j, i, c r, t}\right)^{3}-1.319 *\left(1-T r_{j, i, c r, t}\right)^{6}\right] / T r_{j, i, c r, t}$

$+\omega_{i} *\left[-4.78522 *\left(1-\operatorname{Tr}_{j, i, c r, t}\right)+0.413999 *\left(1-\operatorname{Tr}_{j, i, c r, t}\right)^{1.5}\right.$

$\left.\left.-8.91239 *\left(1-\operatorname{Tr}_{j, i, c r, t}\right)^{3}-4.98662 *\left(1-\operatorname{Tr}_{j, i, c r, t}\right)^{6}\right] / \operatorname{Tr}_{j, i, c r, t}\right) \quad \forall j, i \in P s C, c r, t$ 
The separation temperature is the arithmetic average of the initial boiling point and end boiling points relevant to each cut,

$$
T_{j, c r, t}=\frac{T E_{j, c r, t}+T I_{j, c r, t}}{2} \quad \forall j, c r, t
$$

Moreover, the temperature decreases along the CDU column from bottom to top, which is expressed as,

$$
T_{j, c r, t} \geq T_{j+1, c r, t} \quad \forall j, c r, t
$$

\subsection{The LP Planning Model}

The next layer in the model formulation is the planning model. This includes the set of equations for calculating the product yields from each process unit, except the CDU, as well as stream properties calculations and product blending.

The yield of process unit $k$ is calculated using a coefficient multiplied by the unit feed $l$ ', to give the unit product stream $l$

$$
S T_{l, k, c r, t}=a_{k, l, l^{\prime}, c r} * S T_{l^{\prime}, k, c r, t} \quad \forall k, c r, t
$$

The requirement for capacity of unit $k$ is ensured using the following constraint,

$$
\sum_{l} S T_{l, k, c r, t} \leq \text { capacity }_{k} \quad \forall k, c r, t
$$

The interconnections between the process units are managed using several splitters and mixers. The splitters use the following equation,

$$
S T_{l^{\prime}, \text { sep }, c r, t}=\sum_{l} S T_{l, s e p, c r, t} \quad \forall s e p, c r, t
$$

while the mixers use the following equation,

$$
\sum_{l} S T_{l, m i x, c r, t}=S T_{l^{\prime}, \text { mix }, c r, t} \quad \forall \text { mix }, c r, t
$$

Product blending is a mixer unit, but is distinguished by the final product streams $p$,

$$
\sum_{l} S T_{l, k, c r, t}=S T_{p, c r, t} \quad \forall p, c r, t
$$

The product properties are checked against the product specification $\mathrm{PR}_{r, p}$ using the following constraints 


$$
\begin{array}{ll}
S T_{p, c r, t} * P R_{r, p, t} \leq \sum_{l^{\prime}, k} P r_{r, l^{\prime}, k, c r, t} * S T_{l^{\prime}, k, c r, t} & \forall p, c r, t \\
S T_{p, c r, t} * P R_{r, p, t} \geq \sum_{l^{\prime}, k} P r_{r, l^{\prime}, k, c r, t} * S T_{l^{\prime}, k, c r, t} & \forall p, c r, t
\end{array}
$$

Typically the planning model will include checking the feedstock availability, meeting the product demands and the objective function. However, these constraints and equations are moved to the next layer of the model as part of the extension from single period to multi period time horizon.

\subsection{MultiPeriod extension}

The multi period layer is primarily based on the approach proposed by Eridirk-Dogan \& Grossmann ${ }^{16}$. The idea is to determine the length of the processing times for each crude oil, and to use traveling salesman constraints to determine the sequence for processing crude in each time period and identifying the link to break and connect the sequence to the adjacent time periods. The objective function consists of maximizing the profit. When there are no subcycles in any time period, the changeovers are properly accounted for in each time period and any possible crossovers. Otherwise, subtour elimination constraints are added until all subcycles are eliminated. Also, since the duration of the changeovers is relatively modest, we assume for simplicity that changeovers cannot cross periods. The extension to handle this case can be readily handled (see Lima et $\mathrm{al}^{21}$ and Kopanos et $\mathrm{al}^{22}$ ).The proposed MINLP model is described below.

\subsubsection{Assignment}

The binary variable $Y P_{c r, t}$ is for deciding whether crude $\mathrm{cr}$ is processed at time period $t$. It is used in the following constraint to set the crude processing time $\theta_{c r, t}$ to zero if the crude oil is not selected. The length of the processing time is limited by the length of the time period given by $\mathrm{Ht}$,

$$
\theta_{c r, t} \leq H t * Y P_{c r, t} \quad \forall c r, t
$$

The maximum crude oil availability $A U F C r_{c r, t}$ or minimum requirements $A L F C r_{c r, t}$ are checked using the crude oil processing rate $F C r_{c r, t}$ multiplied by the processing time $\theta_{c r, t}$,

$$
\begin{array}{ll}
F C r_{c r, t} * \theta c r, t \geq A L F C r_{c r, t} & \forall c r, t \\
F C r_{c r, t} * \theta c r, t \leq A U F C r_{c r, t} & \forall c r, t
\end{array}
$$

The crude processing rate is linked to the CDU model as follows,

$$
\begin{array}{ll}
F C r_{c r, t}=F_{1, t o t a l, c r, t} & \forall c r, t \\
F C r_{c r, t} * z t_{i, c r, t}=F_{1, i, c r, t} & \forall i, c r, t
\end{array}
$$


The quantities of product $p, X P_{p, c r, t}$, are calculated by multiplying the production rate $S T_{p, c r, t}$ by the processing time $\theta_{c r, t}$,

$$
X P_{p, c r, t}=S T_{p, c r, t} * \theta_{c r, t} \quad \forall p, c r, t
$$

$F C r_{c r, t}$ and $S T_{p, c r, t}$ are the two variables linking this outer MINLP layer, namely equations (33)-(37), to the remaining model equations from the planning and FI layers, namely equations (1)-(9) and (14)-(31).

\subsubsection{Inventory}

The inventory of product $p, \operatorname{In} v_{p, t}$, is accounted for at the end of each time period $t$, using the initial inventory at the start of the period $I n v i_{p, t}$ and the product production $X P_{p, c r, t}$.

$$
I n v_{p, t}=I n v i_{p, t}+\sum_{c r} X P_{p, c r, t} \quad \forall p, t
$$

The initial inventory Invi $i_{p, t}$ is the inventory of the previous period after any sales $\left(S l_{p, t-1}\right)$ at the end of that period,

$$
I n v i_{p, t}=I n v_{p, t-1}-S l_{p, t-1} \quad \forall p, t
$$

For the purpose of the planning model, and since we are accounting for demand at the end of each period, the change of inventory is aggregated by multiplying the time period duration $H t$ times the inventory Inv. This represents the area under the curve, which is a conservative estimate for the purpose of the inventory cost.

$$
A r \operatorname{Inv} v_{p, t}=H t *\left(\operatorname{Invi}_{p, t}+\sum_{c r} X P_{p, c r, t}\right) \quad \forall p, t
$$

\subsubsection{Demand}

The demand for product $p$ is met using the sales variable $S l_{p, t}$ at the end of each time period $t$. The following constraints are used to meet any minimum or maximum demand requirements, Demand $L_{p, t}$ and Demand $U_{p, t}$, respectively.

$$
\begin{array}{lr}
S l_{p, t} \geq \operatorname{Demand}_{p, t} & \forall p, t \\
S l_{p, t} \leq \operatorname{Demand}_{p, t} & \forall p, t
\end{array}
$$

\subsubsection{Sequence}

The sequence of processing the available crude oils is modeled next. The new binary variable $Z P_{c r, c c r, t}$ is defined as 1 when crude $c r$ is followed by crude $c c r$ in time period $t$. For that to be true, both crude oils $c r$ and $c c r$ should be assigned to that time period and their $Y P_{c r, t}$ variables are 1. 


$$
\begin{array}{ll}
Y P_{c r, t}=\sum_{c c r} Z P_{c r, c c r, t} & \forall c r, t \\
Y P_{c c r, t}=\sum_{c r} Z P_{c r, c c r, t} & \forall c c r, t
\end{array}
$$

These constraints represent the assignment constraints of the travelling salesman problem.

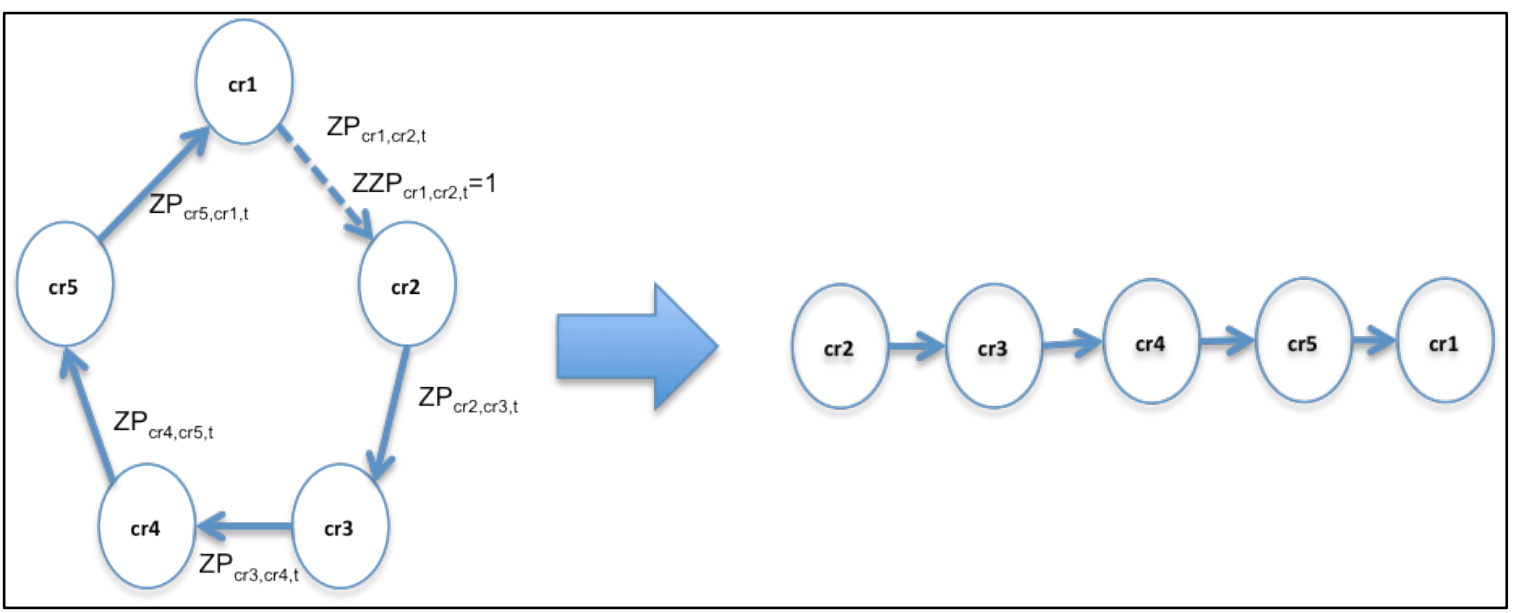

Figure 3 Crude oil processing cycle order and resulting optimal processing sequence

If there are no subcycles, this will create a cyclic sequence in each time period. To account for a single crude oil requiring a whole time period, the following constraints are used,

$$
\begin{array}{ll}
Y P_{c r, t} \geq Z P_{c r, c c r, t} & \forall c r, c c r, t \\
Y P_{c c r, t}+Z P_{c r, c r, t} \leq 1 & \forall c r \neq c c r, t \\
Z P_{c r, c r, t} \geq Y P_{c r, t}-\sum_{c c r \neq c r} Y P_{c c r, t} & \forall c r, t
\end{array}
$$

The link to be broken in each closed sequence is defined by the new binary variable $Z Z P_{c r, c r, t .}$. Each time period will have one link broken using the following constraint,

$$
\sum_{c r} \sum_{c c r} Z Z P_{c r, c c r, t}=1 \quad \forall t
$$

as long as the link exists, that is

$$
Z Z P_{c r, c c r, t} \leq Z P_{c r, c c r, t} \quad \forall c r, c c r, t
$$


To establish the sequence, the first and last crude oil are identified as $x F_{c c r, t}$ and $x L_{c r, t}$ using the binary variable $Z Z P_{c r, c c r, t}$ as follows,

$$
\begin{array}{ll}
x F_{c c r, t} \geq \sum_{c r} Z Z P_{c r, c c r, t} & \forall c c r, t \\
\sum_{c c r} x F_{c c r, t}=1 & \forall t \\
x L_{c r, t} \geq \sum_{c c r} Z Z P_{c r, c c r, t} & \forall c r, t \\
\sum_{c r} x L_{c r, t}=1 & \forall t
\end{array}
$$

Identifying the first and last crude oils also determines any crude oil that crosses over to the next time period. This ensures that the time balance is correctly accounted for. The binary variable $Z Z Z_{c r, c c r, t}$ indicates as follows the link that crosses over two time periods,

$$
\begin{array}{ll}
\sum_{c r} Z Z Z_{c r, c c r, t}=x F_{c c r, t+1} & \forall c c r, t \\
\sum_{c c r} Z Z Z_{c r, c c r, t}=x L_{c r, t} & \forall c r, t
\end{array}
$$

\subsubsection{Transition time \& time balance}

Using the given changeover times $\tau_{c r, c c r}$ from crude $c r$ to crude $c c r$, the total transition time Trans $_{t}$ in each period $t$ is calculated as follows

$$
\operatorname{Trans}_{t}=\sum_{c r} \sum_{c c r} \tau_{c r, c c r} * Z P_{c r, c c r, t}-\sum_{c r} \sum_{c c r} \tau_{c r, c c r} * Z Z P_{c r, c c r, t} \quad \forall t
$$

The time balance accounts for the total processing time, the transition time and any crossovers to ensure continuous operation and no idle time as follows,

$$
\sum_{c r} \theta_{c r, t}+\operatorname{Trans}_{t}+\sum_{c r} \sum_{c c r} t_{a u} u_{c r, c c r} * Z Z Z_{c r, c c r, t}=H t \quad \forall t
$$

\subsubsection{Objective function}

Finally, the objective function expresses the refinery profits as the product sales minus the costs of product inventory, crude oil, unit operation and net transition times. 


$$
\begin{aligned}
\text { Profit } & =\sum_{t} \sum_{p} \text { Price }_{p, t} * S l_{p, t}-\sum_{t} \sum_{p} \operatorname{ArInv}_{p, t} * C \operatorname{Inv}_{p, t} \\
& -\sum_{t} \sum_{c r} C F C r_{c r, t} * F C r c r, t * \theta_{c r, t}-\sum_{t} \sum_{c r} C O p C_{c r, t} * F C r c r, t * \theta_{c r, t} \\
& -\sum_{t} \sum_{c r} \sum_{c c r} C \operatorname{Trans}_{c r, c c r} * Z P_{c r, c c r, t} \\
& -\sum_{t} \sum_{c r} \sum_{c c r} C \operatorname{Trans}_{c r, c c r} *\left(Z Z Z_{c r, c c r, t}-Z Z P_{c r, c c r, t}\right)
\end{aligned}
$$

\subsubsection{Subtour elimination constraints}

For the cases when the model results yields subcycles in a given week, subtour elimination constraints need to be added. For any resulting subcycle $m$ in time period $t \mathrm{SC}_{m, t}$, the following subtour elimination constraint is added to the model

$$
\sum_{c r, c c r \in S C_{m, t}} Z P_{c r, c c r, t} \leq\left|S C_{m, t}\right|-1 \quad c r \neq c c r, \forall S C_{m, t}
$$

The model is appended with this constraint until there are no subcycles in resulting crude processing sequence. It should be noted that by simply adding subtour elimination constraints instead of performing a rigorous branch and bound search, the resulting solution is not guaranteed to be optimal. However, as the effect of the transition costs is not usually very large, optimal or near optimal solutions are obtained whose quality can in fact be measured by the $\%$ decrease in the profit. This decrease in profit represents an upper bound to the optimality gap since the first solution with subcycles yields an upper bound to the optimum.

\section{Example \& Discussion}

To demonstrate the performance of the proposed MINLP model, several examples are presented in this section. Equations (1)-(9) and (14)-(58) define the MINLP model for the multiperiod refinery planning model, which extends the single-period NLP model by Alattas, Grossmann \& Palou-Rivera (2011).

In the first example, 5 crude oils are available for processing to produce fuel gas (FG), regular gasoline (RG), premium gasoline (PG), distillate (Dist), fuel oil (FO) and treated residue (HTR). The crude oils, crude1 through crude5, are listed in Appendix A. The planning horizon is 4 weeks or 4 time periods. The other model data are listed in the appendix

The model is solved using GAMS/DICOPT 23.3.3 as the solver with CONOPT and CPLEX for solving the NLP and MILP subproblems, respectively. The MINLP model consists of 13,680 variables and 15,047 equations. The nonlinear variables are $28 \%$ of the total number of variables, similar to the ratio in the single-period planning model. There are 900 binary variables, accounting for $6.6 \%$ of the total 
variables. The total time required by DICOPT was 37.5 seconds (94\% NLP and 6\% MIP), involving 3 major iterations.

The model generates a profitable production plan that is summarized in Table 1, while the crude oil processing rate, time and total feed are listed in Table 2. The product sales and inventory are summarized in Table 3

Table 1 Example 1 Economic results (\$1000)

\begin{tabular}{|l|r|}
\hline Profit & 23994.3 \\
\hline Sales & 223684.0 \\
\hline Crude oil cost & 162988.0 \\
\hline Other feedstock cost & 446.3 \\
\hline Inventory cost & 1265.2 \\
\hline Operating cost & 32510.8 \\
\hline Transition cost & 2480.0 \\
\hline
\end{tabular}

Table 2 Example 1 Feed and processing time information

\begin{tabular}{|c|c|c|c|c|c|c|}
\hline & & Crude & week1 & week2 & week3 & week4 \\
\hline \multirow[t]{10}{*}{ Flow } & \multirow{5}{*}{$\begin{array}{l}\text { Processing } \\
\text { rate } \\
(1000 \text { 's } \\
\text { BPD) }\end{array}$} & CRUDE1 & 100.0 & 100.0 & 100.0 & 100.0 \\
\hline & & CRUDE2 & 100.0 & 100.0 & 100.0 & 100.0 \\
\hline & & CRUDE3 & 100.0 & 100.0 & 100.0 & 100.0 \\
\hline & & CRUDE6 & 98.0 & 98.0 & 98.0 & 98.0 \\
\hline & & CRUDE8 & 99.7 & 99.7 & 99.7 & 99.7 \\
\hline & \multirow{5}{*}{$\begin{array}{l}\text { Total Flow } \\
(1000 \text { 's } \\
\text { bbl) }\end{array}$} & CRUDE1 & 297.5 & 289.2 & 289.2 & 289.2 \\
\hline & & CRUDE2 & 70.0 & 70.0 & 70.0 & 70.0 \\
\hline & & CRUDE3 & 70.0 & 70.0 & 70.0 & 70.0 \\
\hline & & CRUDE6 & 70.0 & 70.0 & 70.0 & 70.0 \\
\hline & & CRUDE8 & 70.0 & 70.0 & 70.0 & 70.0 \\
\hline \multirow[t]{5}{*}{ Time } & \multirow{5}{*}{$\begin{array}{l}\text { Processing } \\
\text { time } \\
\text { (hr) }\end{array}$} & CRUDE1 & 71.4 & 69.4 & 69.4 & 69.4 \\
\hline & & CRUDE2 & 16.8 & 16.8 & 16.8 & 16.8 \\
\hline & & CRUDE3 & 16.8 & 16.8 & 16.8 & 16.8 \\
\hline & & CRUDE6 & 17.1 & 17.1 & 17.1 & 17.1 \\
\hline & & CRUDE8 & 16.9 & 16.9 & 16.9 & 16.9 \\
\hline
\end{tabular}

Table 3 Example 1 Product quantities and inventory

\begin{tabular}{|l|l|r|r|r|r|}
\hline \multirow{3}{*}{$\begin{array}{l}\text { Sales } \\
(1000 \text { 's bbl) }\end{array}$} & Product & week1 & week2 & week3 & week4 \\
\cline { 2 - 6 } & FG & 100.1 & 99.7 & 102.6 & 92.5 \\
\cline { 2 - 6 } & RG & 140.0 & 235.7 & 216.0 & 119.0 \\
\cline { 2 - 6 } & Dist & 70.0 & 245.0 & 133.3 & 210.5 \\
\cline { 2 - 6 } & FO & 16.3 & 13.0 & 5.7 & 31.8 \\
\cline { 2 - 6 } & 93.9 & 92.2 & 92.2 & 92.9 \\
\hline
\end{tabular}




\begin{tabular}{|l|l|r|r|r|r|}
\cline { 2 - 5 } & HTR & 30.5 & 30.5 & 30.5 & 30.5 \\
\hline \multirow{4}{*}{$\begin{array}{l}\text { Inventories } \\
\text { (1000's bbl) }\end{array}$} & FG & 100.1 & 99.7 & 102.6 & 92.5 \\
\cline { 2 - 6 } & PG & 182.8 & 235.7 & 216.0 & 119.0 \\
\cline { 2 - 6 } & RG & 164.0 & 245.0 & 133.3 & 210.5 \\
\cline { 2 - 6 } & Dist & 16.3 & 13.0 & 5.7 & 31.8 \\
\cline { 2 - 6 } & FO & 93.9 & 92.2 & 92.2 & 92.9 \\
\cline { 2 - 6 } & HTR & 30.5 & 30.5 & 30.5 & 30.5 \\
\hline
\end{tabular}

Figure 4 shows the sequence of crude oils and their respective transition times. In this run, the model resulted in subcycles for weeks 2,3 and 4, but not in week 1 . The subcycle is the same in all those time periods. To eliminate the subcycles, we add subtour elimination constraints, Equation (59). This leads to a decrease of the profit from $\$ 23.99 \mathrm{MM}$ to $\$ 23.69 \mathrm{MM}$ (i.e. $1.3 \%$ optimality gap), as shown in Table 4 and Figure 5 . Note that the resulting sequence eliminated the subcycles and altered the original sequence of week1.

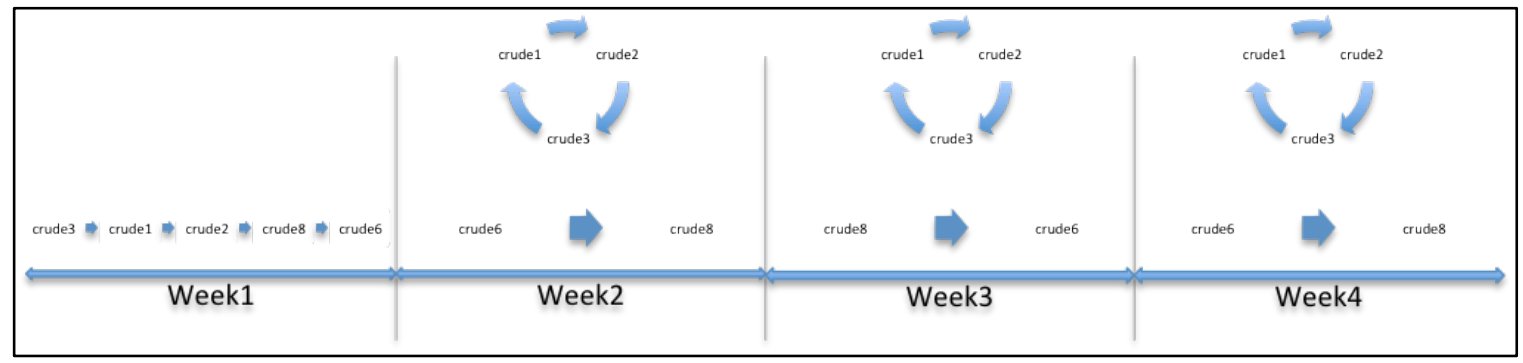

Figure 4 Example 1 Crude processing sequence

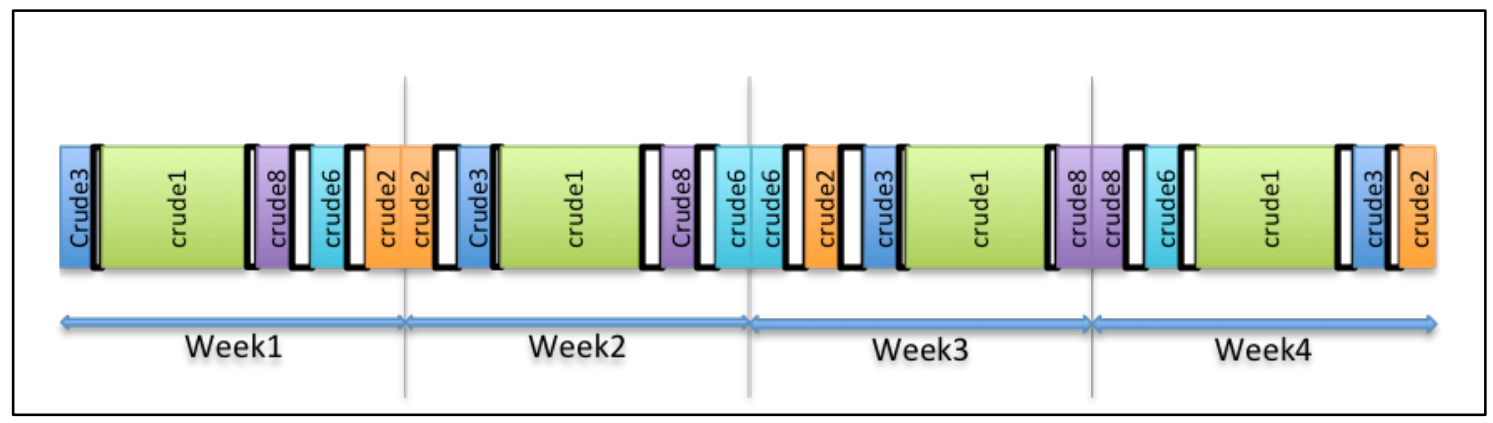

Figure 5 Example 1 Crude processing sequence after subcycle elimination

Table 4 Example 1 Economic results (\$1000's) after subcycle elimination

\begin{tabular}{|l|r|}
\hline Profit & 23690.0 \\
\hline Sales & 223279.0 \\
\hline Crude oil cost & 162675.0 \\
\hline Other feedstock cost & 446.3 \\
\hline Inventory cost & 1263.1 \\
\hline
\end{tabular}




\begin{tabular}{|l|r|}
\hline Operating cost & 32464.5 \\
\hline Transition cost & 2740.0 \\
\hline
\end{tabular}

\subsection{Longer time horizon}

To test the robustness of the model, two additional examples are considered. The first has a longer time horizon, while the other uses a different set of crude oils.

In example 2 the time horizon is extended to 6 weeks or 6 time periods. The data for the two additional time periods are listed in Appendix A. Table 5 summarizes the economic results of the longer horizon, showing a profitable production plan. Additional results are listed in Table 6 and Table 7 for the crude oil feed, processing time, sales and inventory figures. This example exhibits the same crude oil sequence and subcycles observed in example 1, as seen in Figure 6.

Table 5 Example 2 Economic results (\$1000's)

\begin{tabular}{|l|r|}
\hline Profit & 36845.5 \\
\hline Sales & 338346.0 \\
\hline Crude oil cost & 244169.0 \\
\hline Other feedstock cost & 761.0 \\
\hline Inventory cost & 2019.8 \\
\hline Operating cost & 50830.4 \\
\hline Transition cost & 3720.0 \\
\hline
\end{tabular}

Table 6 Example 2 Feed and processing time information

\begin{tabular}{|c|c|c|c|c|c|c|c|c|}
\hline & & Crude & week1 & week2 & week3 & week4 & week5 & week6 \\
\hline \multirow[t]{10}{*}{ Flow } & \multirow{5}{*}{$\begin{array}{l}\text { Processing } \\
\text { rate } \\
\text { (1000's } \\
\text { BPD) }\end{array}$} & CRUDE1 & 100.0 & 100.0 & 100.0 & 100.0 & 100.0 & 100.0 \\
\hline & & CRUDE2 & 100.0 & 100.0 & 100.0 & 100.0 & 100.0 & 100.0 \\
\hline & & CRUDE3 & 100.0 & 100.0 & 100.0 & 100.0 & 100.0 & 100.0 \\
\hline & & CRUDE6 & 98.0 & 98.0 & 98.0 & 98.0 & 98.0 & 98.0 \\
\hline & & CRUDE8 & 99.7 & 99.7 & 99.7 & 99.7 & 99.7 & 99.7 \\
\hline & \multirow{5}{*}{$\begin{array}{l}\text { Total Flow } \\
\text { (1000's } \\
\text { bbl) }\end{array}$} & CRUDE1 & 297.5 & 289.2 & 289.2 & 289.2 & 289.2 & 289.2 \\
\hline & & CRUDE2 & 70.0 & 70.0 & 70.0 & 70.0 & 70.0 & 70.0 \\
\hline & & CRUDE3 & 70.0 & 70.0 & 70.0 & 70.0 & 70.0 & 70.0 \\
\hline & & CRUDE6 & 70.0 & 70.0 & 70.0 & 70.0 & 70.0 & 70.0 \\
\hline & & CRUDE8 & 70.0 & 70.0 & 70.0 & 70.0 & 70.0 & 70.0 \\
\hline \multirow[t]{5}{*}{ Time } & \multirow{5}{*}{$\begin{array}{l}\text { Processing } \\
\text { time } \\
\text { (hr) }\end{array}$} & CRUDE1 & 71.4 & 69.4 & 69.4 & 69.4 & 69.4 & 69.4 \\
\hline & & CRUDE2 & 16.8 & 16.8 & 16.8 & 16.8 & 16.8 & 16.8 \\
\hline & & CRUDE3 & 16.8 & 16.8 & 16.8 & 16.8 & 16.8 & 16.8 \\
\hline & & CRUDE6 & 17.1 & 17.1 & 17.1 & 17.1 & 17.1 & 17.1 \\
\hline & & CRUDE8 & 16.9 & 16.9 & 16.9 & 16.9 & 16.9 & 16.9 \\
\hline
\end{tabular}


Table 7 Example 2 Product quantities and inventory

\begin{tabular}{|l|l|r|r|r|r|r|r|}
\hline & Product & week1 & week2 & week3 & week4 & Week5 & Week6 \\
\hline \multirow{3}{*}{$\begin{array}{l}\text { Sales } \\
\text { bbl) }\end{array}$} & FG & 100.1 & 99.7 & 102.6 & 102.6 & 102.6 & 102.6 \\
\cline { 2 - 7 } & PG & 140.0 & 235.7 & 216.0 & 119.0 & 280.0 & 249.0 \\
\cline { 2 - 7 } & RG & 70.0 & 245.0 & 70.9 & 84.0 & 245.0 & 133.3 \\
\cline { 2 - 7 } & Dist & 16.3 & 13.0 & 5.7 & 5.7 & 5.7 & 5.7 \\
\cline { 2 - 7 } & FO & 93.9 & 92.2 & 92.2 & 92.2 & 92.2 & 92.2 \\
\cline { 2 - 8 } & HTR & 30.5 & 30.5 & 30.5 & 30.5 & 30.5 & 30.5 \\
\hline \multirow{3}{*}{$\begin{array}{l}\text { Inventories } \\
\text { bbl) }\end{array}$} & FG & 100.1 & 99.7 & 102.6 & 102.6 & 102.6 & 102.6 \\
\cline { 2 - 8 } & PG & 182.8 & 235.7 & 216.0 & 216.0 & 313.0 & 249.0 \\
\cline { 2 - 8 } & RG & 164.0 & 245.0 & 133.3 & 195.7 & 245.0 & 133.3 \\
\cline { 2 - 8 } & Dist & 16.3 & 13.0 & 5.7 & 5.7 & 5.7 & 5.7 \\
\cline { 2 - 8 } & FO & 93.9 & 92.2 & 92.2 & 92.2 & 92.2 & 92.2 \\
\cline { 2 - 7 } & HTR & 30.5 & 30.5 & 30.5 & 30.5 & 30.5 & 30.5 \\
\hline
\end{tabular}

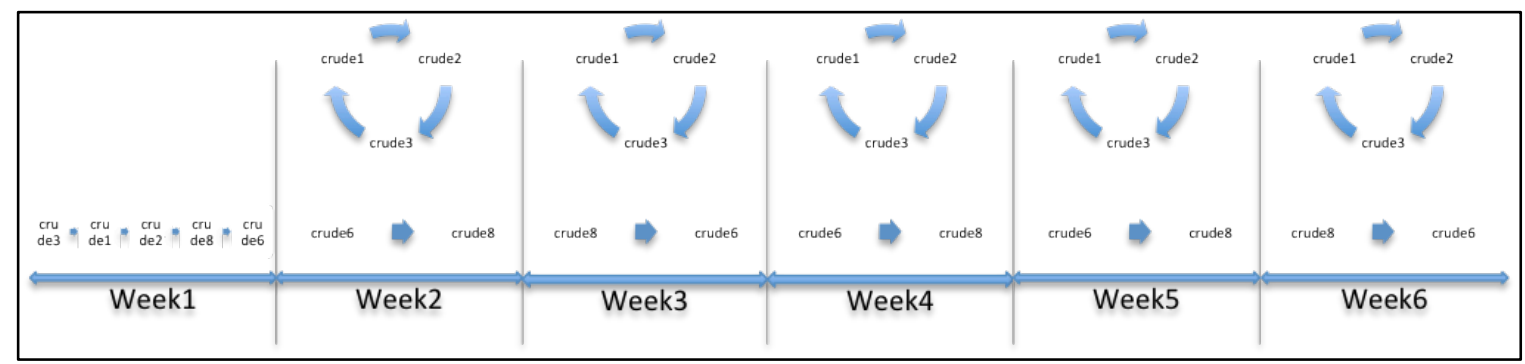

Figure 6 Example 2 Crude processing sequence

In terms of models statistics, the model increased to 22,757 equations and 20,522 variables, with 1350 of them being binary. The ratio of the nonlinear and discrete variables stayed at $28 \%$ and $6.6 \%$ respectively. The total time by DICOPT increased to 113.13 seconds (95\% NLP and 5\% MIP), requiring 3 major iterations.

Similar to example 1, the subcycle elimination constraints of Equation (59) are applied to this example reducing the profit from $\$ 36.84 \mathrm{MM}$ to $\$ 36.41 \mathrm{MM}$ (i.e. $1.2 \%$ optimality gap), and yielding a new crude processing sequence, as shown in Table 8 and Figure 7.

Table 8 Example 2 Economic results (\$1000's) after subcycle elimination

\begin{tabular}{|l|r|}
\hline Profit & 36413.4 \\
\hline Sales & 337908.0 \\
\hline Crude oil cost & 243857.0 \\
\hline Other feedstock cost & 760.0 \\
\hline Inventory cost & 2016.3 \\
\hline Operating cost & 50761.5 \\
\hline Transition cost & 4100.0 \\
\hline
\end{tabular}




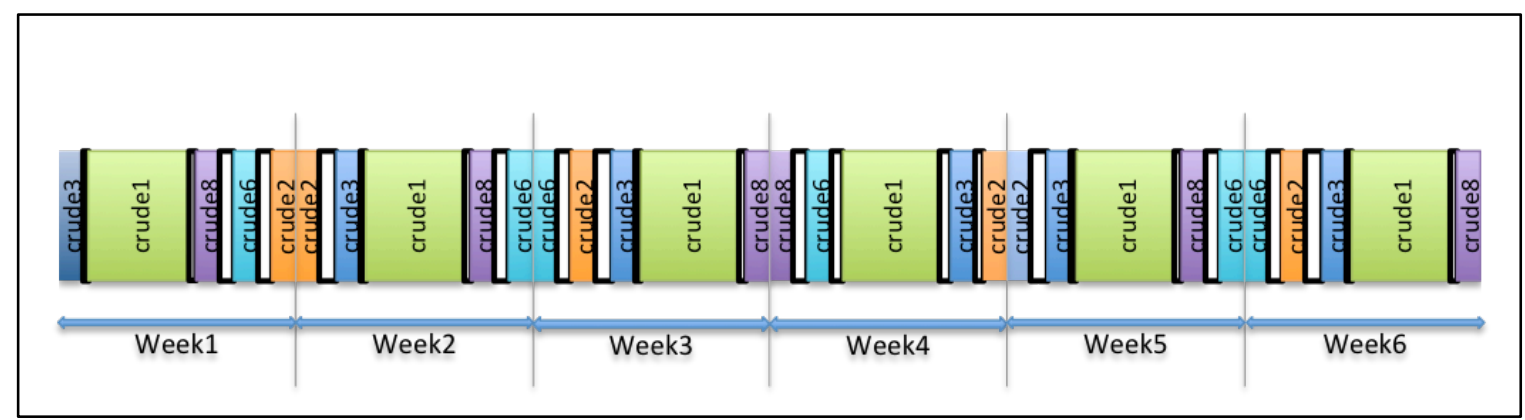

Figure 7 Example 2 Crude processing sequence after subcycle elimination

\subsection{Modified crude oils run}

The other criterion used to test robustness is changing the available crude oils. In example 3 , the base case of 4 weeks/4 time periods horizon is used, but with 4 different crude oils. The economics of the profitable scenario calculated by the model is listed in Table 9. The feed rate, processing rate, sales and inventory results are listed in Table 10 and Table 11.

Table 9 Example 3 Economic results (\$1000's)

\begin{tabular}{|l|r|}
\hline Profit & 28855.1 \\
\hline Sales & 236323.0 \\
\hline Crude oil cost & 172212.0 \\
\hline Other feedstock cost & 425.9 \\
\hline Inventory cost & 1309.2 \\
\hline Operating cost & 31700.2 \\
\hline Transition cost & 1820.0 \\
\hline
\end{tabular}

Table 10 Example 3 Feed and processing time information

\begin{tabular}{|c|c|c|c|c|c|c|}
\hline & & Crude & week1 & week2 & week3 & week4 \\
\hline \multirow[t]{8}{*}{ Flow } & \multirow{4}{*}{$\begin{array}{l}\text { Processing } \\
\text { rate } \\
(1000 \text { 's } \\
\text { BPD) }\end{array}$} & CRUDE1 & 100.0 & 100.0 & 100.0 & 100.0 \\
\hline & & CRUDE2 & 100.0 & 100.0 & 100.0 & 100.0 \\
\hline & & CRUDE4 & 100.0 & 100.0 & 100.0 & 100.0 \\
\hline & & CRUDE5 & 100.0 & 100.0 & 100.0 & 100.0 \\
\hline & \multirow{4}{*}{$\begin{array}{l}\text { Total Flow } \\
(1000 \text { 's } \\
\text { bbl) }\end{array}$} & CRUDE1 & 70.0 & 70.0 & 70.0 & 70.0 \\
\hline & & CRUDE2 & 70.0 & 70.0 & 70.0 & 70.0 \\
\hline & & CRUDE4 & 70.0 & 70.0 & 70.0 & 70.0 \\
\hline & & CRUDE5 & 373.3 & 406.7 & 344.2 & 406.7 \\
\hline \multirow[t]{4}{*}{ Time } & \multirow{4}{*}{$\begin{array}{l}\text { Processing } \\
\text { time } \\
\text { (hr) }\end{array}$} & CRUDE1 & 16.8 & 16.8 & 16.8 & 16.8 \\
\hline & & CRUDE2 & 16.8 & 16.8 & 16.8 & 16.8 \\
\hline & & CRUDE4 & 16.8 & 16.8 & 16.8 & 16.8 \\
\hline & & CRUDE5 & 89.6 & 97.6 & 82.6 & 97.6 \\
\hline
\end{tabular}


Table 11 Example 3 Product quantities and inventory

\begin{tabular}{|l|l|r|r|r|r|}
\hline & Product & week1 & week2 & week3 & week4 \\
\hline \multirow{3}{*}{$\begin{array}{l}\text { Sales } \\
\text { (1000's bbl) }\end{array}$} & FG & 97.2 & 103.3 & 95.8 & 94.2 \\
\cline { 2 - 6 } & PG & 140.0 & 261.7 & 208.8 & 119.0 \\
\cline { 2 - 6 } & RG & 70.0 & 245.0 & 129.4 & 232.0 \\
\cline { 2 - 6 } & Dist & 26.8 & 27.0 & 15.2 & 50.1 \\
\cline { 2 - 6 } & FO & 102.3 & 109.1 & 96.4 & 110.1 \\
\cline { 2 - 6 } & HTR & 18.9 & 18.9 & 18.9 & 18.9 \\
\hline \multirow{3}{*}{$\begin{array}{l}\text { Inventories } \\
\text { (1000's bbl) }\end{array}$} & FG & 97.2 & 103.3 & 95.8 & 94.2 \\
\cline { 2 - 6 } & PG & 192.0 & 261.7 & 208.8 & 119.0 \\
\cline { 2 - 6 } & RG & 155.8 & 245.0 & 129.4 & 232.0 \\
\cline { 2 - 6 } & Dist & 26.8 & 27.0 & 15.2 & 50.1 \\
\cline { 2 - 6 } & FO & 102.3 & 109.1 & 96.4 & 110.1 \\
\cline { 2 - 6 } & HTR & 18.9 & 18.9 & 18.9 & 18.9 \\
\hline
\end{tabular}

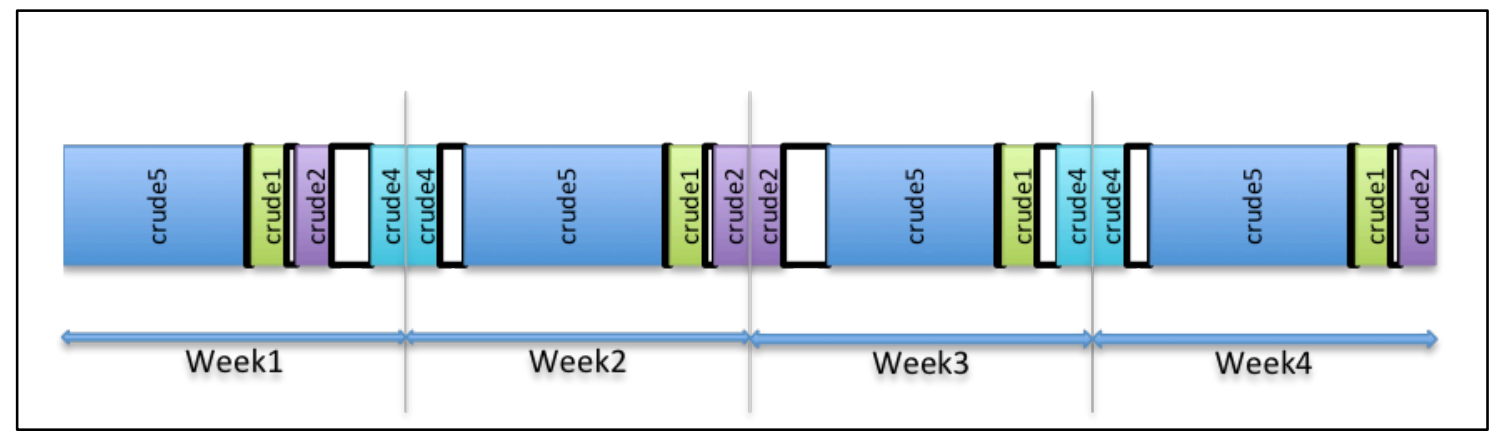

Figure 8 Example 3 Crude processing sequence

The fewer, but different, crude oils translated into a smaller model, with 12,005 equations and 10,937 variables, with 704 of them being binary. The same ratio of nonlinear variables is generated here $(28 \%)$, but slightly smaller ratio of discrete variables (6.4\%). The solver DICOPT required shorter time at 27.69 seconds (94\% NLP and 6\% MIP), requiring 3 major iterations.

\subsection{Impact of the FI disjunctive formulation}

As noted earlier, the previous work (Alattas et al, 2011) utilized the Heaviside function in Equation (12) instead of the current mixed-integer formulation (14)-(16) for the FI value choice. This resulted in an NLP model versus an MINLP model. To evaluate the impact on the solution and solver time by reducing the number of $0-1$ variables in the multiperiod MINLP model, example 1 with the 5 crude oils and 4 week time horizon was solved using the Heaviside function formulation. The results are the same as in Table 1 through Table 4 and Figure 4. Thus, both formulations give the same results. 
On the other hand, the two models differed in terms of the size of the MINLP model. The MINLP model using the Heaviside function for the FI disjunction included 12,347 constraints and 12,520 variables (320 binary). In contrast, the MINLP model using the mixed-integer constraints for the FI disjunction included 15,047 constraints and 13,680 variables (900 binary variables). However, it should be noted that despite the reduction of size with the Heaviside function, it actually includes a larger number of nonlinear terms, which in turn tend to be ill-conditioned. Therefore, despite the reduction in size and its relatively robust performance in the single-period NLP model, the Heaviside function formulation either failed to converge or required much longer solution time using the default options of solver DICOPT/CPLEX since many NLP subproblems were found to be infeasible, presumably due the difficulties in handling this function. Setting the option for DICOPT to linearize infeasible NLP subproblems gave the solution in 18.23 seconds. Though shorter than example 1 with the default DICOPT/CPLEX options, the Heaviside formulation in the multiperiod model is less robust than the proposed MINLP model in which linear mixed-integer constraints replace ill-conditioned nonlinearities.

\section{Conclusion}

In this paper we have addressed the multiperiod refinery planning problem by extending our previous single period nonlinear planning model that uses the FI model for the CDU. In this work, we replaced the simple Heaviside function formulation for the FI value choice by mixed-integer constraints. This improvement was more natural due the inherent MINLP nature of the multiperiod model making it also more robust.

For the multiperiod extension, the traveling salesman constraints were used to generate the sequence of selected crude oils in each time period. The combination of the FI model with the traveling salesman constraints produced an MINLP multiperiod refinery planning model that proved robust in terms of different planning horizon and different crude oils. However, the model for some crude oil combination produced subcycles. These subcycles were eliminated by adding appropriate subtour elimination constraints, yielding a near optimal solution. Althought the solution time increased from the single period model, the multiperiod MINLP model required reasonable solution times.

Finally, the multiperiod extension of the Heaviside formulation was less robust due to the ill-conditioning of the Heaviside function. The new MINLP formulation is more robust and more general in its application to both singleperiod and multiperiod problems.

\section{Acknowledgment}


Abdulrahman Alattas acknowledges the generous support of the Abu Dhabi National Oil Co. (ADNOC) for funding his Ph.D. research and the financial support by BP Refining Technology for funding this research. 


\section{Nomenclature}

\begin{tabular}{|c|c|}
\hline $\operatorname{ArInv}_{p, t}$ & $\begin{array}{l}\text { The area under the curve of the } \\
\text { inventory of product } p \text { in time period } t\end{array}$ \\
\hline $\mathrm{FCr}_{\mathrm{cr}, \mathrm{t}}$ & $\begin{array}{l}\text { The processing rate of crude cr in time } \\
\text { period } t\end{array}$ \\
\hline $\mathrm{F}_{\mathrm{j}, \mathrm{i}, \mathrm{cr}, \mathrm{t}}$ & $\begin{array}{l}\text { Feed stream of component } i \text { of crude } \mathrm{cr} \\
\text { to crude cut } \mathrm{j} \text { in time period } t\end{array}$ \\
\hline Invi & $\begin{array}{l}\text { The initial inventory of product } \mathrm{p} \text { at } \\
\text { the start of time period } \mathrm{t}\end{array}$ \\
\hline $\operatorname{Inv} v_{p, t}$ & $\begin{array}{l}\text { The inventory of product } \mathrm{p} \text { in time } \\
\text { period } \mathrm{t}\end{array}$ \\
\hline$\alpha_{\mathrm{j}, \mathrm{i}, \mathrm{cr}, \mathrm{t}}$ & $\begin{array}{l}\text { Relative volatility as } \mathrm{K}_{\mathrm{j}, \mathrm{i}, \mathrm{cr}, \mathrm{t}} / \mathrm{K}_{\mathrm{j}, \mathrm{ref}, \mathrm{cr}, \mathrm{t}} \text { in } \\
\text { crude cut } \mathrm{j} \text { for component i from crude } \\
\text { cr at time period t with component ref }\end{array}$ \\
\hline $\mathrm{K}_{\mathrm{j}, \mathrm{i}, \mathrm{cr}, \mathrm{t}}$ & $\begin{array}{l}\text { Equilibrium constant in crude cut } \mathrm{j} \text { for } \\
\text { component i from crude cr at time } \\
\text { period } t\end{array}$ \\
\hline $\mathrm{PB}_{\mathrm{j}, \mathrm{I}, \mathrm{cr}, \mathrm{t}}$ & $\begin{array}{l}\text { Bottom product stream of crude cut } j \\
\text { of component i from crude cr in time } \\
\text { period } t\end{array}$ \\
\hline$P D_{j, i, c r, t}$ & $\begin{array}{l}\text { Top product stream of crude cut } j \text { of } \\
\text { component i from crude cr in time } \\
\text { period } t\end{array}$ \\
\hline Profit & The total refinery profits \\
\hline $\operatorname{Pr}_{r, l^{\prime}, k, c r, t}$ & $\begin{array}{l}\text { Property } \mathrm{r} \text { of the outlet stream l' of } \\
\text { refinery unit } \mathrm{k} \text { for crude feed } \mathrm{cr} \text { in time } \\
\text { period } \mathrm{t}\end{array}$ \\
\hline $\mathrm{PV}_{\mathrm{j}, \mathrm{i}, \mathrm{cr}, \mathrm{t}}$ & $\begin{array}{l}\text { Vapor pressure in crude cut } \mathrm{j} \text { for } \\
\text { component i from crude cr at time } \\
\text { period } t\end{array}$ \\
\hline $\mathrm{Sl}_{\mathrm{p}, \mathrm{t}}$ & The sales of product $\mathrm{p}$ in time period $\mathrm{t}$ \\
\hline $\mathrm{ST}_{\mathrm{l}, \mathrm{k}, \mathrm{cr}, \mathrm{t}}$ & $\begin{array}{l}\text { Stream } l \text { from refinery unit } \mathrm{k} \text { for crude } \\
\text { feed } \mathrm{cr} \text { in time period } \mathrm{t}\end{array}$ \\
\hline $\mathrm{ST}_{\mathrm{p}, \mathrm{cr}, \mathrm{t}}$ & $\begin{array}{l}\text { Refinery product stream } \mathrm{p} \text { for crude } \mathrm{cr} \\
\text { in time period } \mathrm{t}\end{array}$ \\
\hline $\mathrm{TI}_{\mathrm{j}, \mathrm{cr}, \mathrm{t}}, \mathrm{TE}_{\mathrm{j}, \mathrm{cr}, \mathrm{t}}$ & $\begin{array}{l}\text { Initial and end boiling point } \\
\text { temperature values for crude cut } j \text { in } \\
\text { time period } t \text { for crude feed cr }\end{array}$ \\
\hline $\mathrm{T}_{\mathrm{j}, \mathrm{cr}, \mathrm{t}}$ & $\begin{array}{l}\text { Separation temperature of crude cut } j \\
\text { for crude cr at time period } t \text { (cut point }\end{array}$ \\
\hline
\end{tabular}




\begin{tabular}{|l|l|}
\hline & temperature) \\
\hline $\operatorname{Trans}_{\mathrm{t}}$ & $\begin{array}{l}\text { The total transition time of time period } \\
\mathrm{t}\end{array}$ \\
\hline $\mathrm{Tr}_{\mathrm{j}, \mathrm{i}, \mathrm{cr}, \mathrm{t}}$ & $\begin{array}{l}\text { Reduced temperature of component } \mathrm{i} \\
\text { from crude cr in crude cut } \mathrm{j} \text { in time } \\
\text { period } \mathrm{t}\end{array}$ \\
\hline $\mathrm{X}_{\mathrm{PB}, \mathrm{j}, \mathrm{icr}, \mathrm{t}}$ & $\begin{array}{l}\text { Component i composition fraction in } \\
\text { bottom product stream PB of crude cut } \\
\text { j from crude cr in time period } \mathrm{t}\end{array}$ \\
\hline $\mathrm{X}_{\mathrm{PD}, \mathrm{j}, \mathrm{irr}, \mathrm{t}}$ & $\begin{array}{l}\text { Component i composition fraction in } \\
\text { top product stream PD of crude cut } \mathrm{j} \\
\text { from crude cr in time period } \mathrm{t}\end{array}$ \\
\hline $\mathrm{XP}_{\mathrm{p}, \mathrm{cr}, \mathrm{t}}$ & $\begin{array}{l}\text { The production rate of produce p from } \\
\text { crude feed cr in time period } \mathrm{t}\end{array}$ \\
\hline$\gamma_{\mathrm{i}, \mathrm{j}, \mathrm{cr}, \mathrm{t}}$ & $\begin{array}{l}\text { Place holder for the selected } \\
\text { fractionation index (FI) value for } \\
\text { component i and crude cr at the crude } \\
\text { cut j in time period } \mathrm{t}\end{array}$ \\
\hline$\theta_{\mathrm{cr}, \mathrm{t}}$ & $\begin{array}{l}\text { Processing time of crude cr in time } \\
\text { period t }\end{array}$ \\
\hline
\end{tabular}

\section{Binary Variables}

\begin{tabular}{|c|c|}
\hline $\mathrm{xF}_{\mathrm{cr}, \mathrm{t}}$ & $\begin{array}{l}0-1 \text { variable whether crude cr is } \\
\text { processed first time period t }\end{array}$ \\
\hline $\mathrm{xL}_{\mathrm{cr}, \mathrm{t}}$ & $\begin{array}{l}0-1 \text { variable whether crude } \mathrm{cr} \text { is } \\
\text { processed last in time period } \mathrm{t}\end{array}$ \\
\hline $\mathrm{Y}_{\mathrm{i}, \mathrm{j}, \mathrm{cr}, \mathrm{trp}}$ & $\begin{array}{l}0-1 \text { variable for stripping (FIs) or } \\
\text { rectifying (FIr) value of the } \\
\text { fractionation index associated with } \\
\text { component i for crude cut } j \text { in time } \\
\text { period t for crude feed cr }\end{array}$ \\
\hline $\mathrm{YP}_{\mathrm{cr}, \mathrm{t}}$ & $\begin{array}{l}0-1 \text { variable whether crude } \mathrm{cr} \text { is } \\
\text { processed in time period } \mathrm{t}\end{array}$ \\
\hline $\mathrm{ZP}_{\mathrm{cr}, \mathrm{ccr}, \mathrm{t}}$ & $\begin{array}{l}0-1 \text { variable whether crude } \mathrm{cr} \text { is } \\
\text { followed by crude ccr in time period } \mathrm{t}\end{array}$ \\
\hline $\mathrm{ZZP}_{\mathrm{cr}, \mathrm{ccr}, \mathrm{t}}$ & $\begin{array}{l}0-1 \text { variable whether the link between } \\
\text { crude cr and ccr is broken in time } \\
\text { period } t\end{array}$ \\
\hline $\mathrm{ZZZ}_{\mathrm{cr}, \mathrm{ccr}, \mathrm{t}}$ & $\begin{array}{l}0-1 \text { variable whether crude } \mathrm{cr} \text { followed } \\
\text { by crude ccr in time period } t \text { crosses } \\
\text { over to the next time period }\end{array}$ \\
\hline
\end{tabular}




\section{Parameters}

\begin{tabular}{|c|c|}
\hline$a_{k, l, l, c r}$ & $\begin{array}{l}\text { Yield equation coefficient for refinery } \\
\text { unit } \mathrm{k} \text { for feed l and outlet feed l' for } \\
\text { crude feed cr }\end{array}$ \\
\hline $\mathrm{ALFCr}_{\mathrm{cr}, \mathrm{t}}$ & $\begin{array}{l}\text { The lower limit on availability of crude } \\
\text { cr in time period } t\end{array}$ \\
\hline $\mathrm{AUFCr}_{\mathrm{cr}, \mathrm{t}}$ & $\begin{array}{l}\text { The upper limit on availability of crude } \\
\text { cr in time period } t\end{array}$ \\
\hline $\mathrm{zt}_{\mathrm{i}, \mathrm{cr}, \mathrm{t}}$ & $\begin{array}{l}\text { The composition of component } i \text { in the } \\
\text { feed crude oil cr in time period } t\end{array}$ \\
\hline capacity ${ }_{k}$ & Capacity of refinery unit k \\
\hline $\mathrm{CFCr}_{\mathrm{cr}, \mathrm{t}}$ & The cost of crude cr in time period $t$ \\
\hline $\operatorname{CInv}_{\mathrm{p}, \mathrm{t}}$ & $\begin{array}{l}\text { The cost of inventory of product } p \text { in } \\
\text { time period } t\end{array}$ \\
\hline $\mathrm{COpC}_{\mathrm{cr}, \mathrm{t}}$ & $\begin{array}{l}\text { The operating cost for crude feed } \mathrm{cr} \text { in } \\
\text { time period } t\end{array}$ \\
\hline CTrans $_{\mathrm{cr}, \mathrm{ccr}}$ & $\begin{array}{l}\text { The transition cost from crude cr to } \\
\text { crude ccr }\end{array}$ \\
\hline DemandL $L_{p, t}$ & $\begin{array}{l}\text { The lower limit of the demand for } \\
\text { product } p \text { in time period } t\end{array}$ \\
\hline Demand $_{p, t}$ & $\begin{array}{l}\text { The upper limit of the demand for } \\
\text { product p in time period } t\end{array}$ \\
\hline $\mathrm{FIr}_{\mathrm{j}}$ & $\begin{array}{l}\text { Fractionation index value for the } \\
\text { rectifying section of crude cut } j\end{array}$ \\
\hline FIs $_{j}$ & $\begin{array}{l}\text { Fractionation index value for the } \\
\text { stripping section of crude cut } j\end{array}$ \\
\hline $\mathrm{Ht}$ & $\begin{array}{l}\text { The length or duration of the time } \\
\text { period }\end{array}$ \\
\hline $\mathrm{M}_{\mathrm{L}}$ & $\begin{array}{l}\text { Big M value when the separation } \\
\text { temperature is greater than the } \\
\text { component boiling point }\end{array}$ \\
\hline $\mathrm{M}_{\mathrm{U}}$ & $\begin{array}{l}\text { Big M value when the separation } \\
\text { temperature is greater than the } \\
\text { component boiling point }\end{array}$ \\
\hline $\mathrm{PC}_{\mathrm{i}}$ & Critical pressure of component i \\
\hline Price $_{\mathrm{p}, \mathrm{t}}$ & The price of product $\mathrm{p}$ in time period $\mathrm{t}$ \\
\hline$P R_{r, p, t}$ & $\begin{array}{l}\text { Property r Specification of refinery } \\
\text { product p in time period } t\end{array}$ \\
\hline $\mathrm{PVA}_{\mathrm{i}}, \mathrm{PVB}_{\mathrm{i}}, \mathrm{PVC}_{\mathrm{i}}$ & $\begin{array}{l}\text { Parameters for the vapor pressure } \\
\text { equation }\end{array}$ \\
\hline $\mathrm{T}_{\mathrm{b}, \mathrm{i}}$ & $\begin{array}{l}\text { Boiling point temperature of } \\
\text { component } \mathrm{i}\end{array}$ \\
\hline$\tau_{\mathrm{cr}, \mathrm{ccr}}$ & The transition time from crude $\mathrm{cr}$ to \\
\hline
\end{tabular}




\begin{tabular}{|l|l|}
\hline & crude ccr \\
\hline$\omega_{\mathrm{i}}$ & Eccentric factor of component $\mathrm{i}$ \\
\hline
\end{tabular}

\section{Sets}

\begin{tabular}{|l|l|}
\hline $\mathrm{HC}_{i}$ & $\begin{array}{l}\text { Set of hydrocarbon components in } \\
\text { crude oil feed to the CDU }\end{array}$ \\
\hline $\mathrm{PsC}_{i}$ & $\begin{array}{l}\text { Set of pseudo-components in crude oil } \\
\text { feed to the CDU }\end{array}$ \\
\hline $\mathrm{SC}_{m, t}$ & $\begin{array}{l}\text { Subset of crude oils in subcycle } m \text { in } \\
\text { time period } t\end{array}$ \\
\hline
\end{tabular}

\section{Subscripts}

\begin{tabular}{|l|l|}
\hline$c r, c c r$ & Crude oil feed \\
\hline$i$ & Crude component i \\
\hline$j$ & Crude cut or separation unit j \\
\hline$k$ & Refinery process unit \\
\hline$l, l^{\prime}$ & Refinery stream \\
\hline$L K_{j}$ & Light key of crude cut $\mathrm{j}$ \\
\hline$H K_{j}$ & Heavy key of crude cut j \\
\hline$p$ & Product \\
\hline$r$ & $\begin{array}{l}\text { Property r of a refinery stream or } \\
\text { product }\end{array}$ \\
\hline$t$ & Time period \\
\hline$m$ & Subcycle of processed crude oils \\
\hline
\end{tabular}




\section{References}

(1) Grossmann, I. E. Enterprise-wide Optimization: A New Frontier in Process Systems Engineering. AIChE J. 2005, 51 (7), 1846-1857.

(2) Kallarth, J. Planning and Scheduling in The Process Industry. In Advanced Planning and Scheduling Solutions in Process Industry; Beek, H. G. A. P. v., Ed.; Springer: New York, 2003.

(3) Coxhead, R. Integrated Planning and Scheduling Systems for The Refining Industry. In Optimization in Industry; Leachman, T. C. a. R., Ed.; Wiley: New York, 1994; Vol. 2.

(4) Zhang, J.; Zhu, X.; Towler, G. A Simultaneous Optimization Strategy for Overall Integration in Refinery Planning. Ind. Eng. Chem. Res. 2001, 40, 26402653.

(5) Shah, N. K.; Li, Z.; Ierapetritou, M. G. Petroleum Refining Operation: Key Issues, Advances and Opplurtunities. In Ind. Eng. Chem. Res. 2011, 50, 11611170.

(6) Favennec, J. Refinery Operation \& Management; Editions Technip: Paris, 2001.

(7) Pelham, R.; Pharris, C. Refinery operation and control: a future vision. In Hydrocarbon Processing, 1996, 75(7), 89-94.

(8) Kelly, JD. Formulating Produciton Planning Models. Chem. Eng. Prog., 2004, 100, 43-50.

(9) Al-Qahtani, K. Y.; Elkamel, A. Planning and Integration of Refinery and Petrochemical Operations. Wiley-VCH Verlag GmbH \& Co.: Weincheim, Germany, 2010.

(10) Zhang, BJ; Hua, B. Effective MILP Model for Oil Refinery-wide Production Planning and Better Energy Utilization. J. Clean Prod. 2007, 15, 439-448.

(11) Kuo, TH.; Chang, CT. Application of Mathematical Programming Model for Integrated Planning and Scheduling of Petroleum Supply Networks. Ind. Eng. Chem. Res., 2008, 47 (6), 1935-1954.

(12) Gyuonnet, P.; Grant, F. H.; Lagajewicz, M. J. Integrated model for refinery planning, oil procuring and product distribution. Ind. Eng. Chem. Res., 2009, 48 (1), 463-482.

(13) Neiro, S. M. S.; Pinto, J. M. Multiperiod optimization for production planning of petroleum refineries. Chem. Eng. Commun. 2005, 192(1), 62-88.

(14) Alattas, A. M.; Grossmann, I. E.; Palou-Rivera, I. Integration of Nonlinear Crude Distillation Unit Models in Refinery Planning Optimization. In Ind. Eng. Chem. Res., 2011, 50 (11), 6860-6870. 
(15) Erdirik-Dogan, M.; Grossmann, I. E. A Decomposition Method for the Simultaneous Planning and Scheduling of Single-Stage Continuous Multiproduct Plants. In Ind. Engl. Chem. Res. 2006, 45 (1), 299-315.

(16) Erdirik -Dogan, M. E.; Grossmann, I. E. Simultaneous planning and scheduling of single-stage multi-product continuous plants with parallel lines. In Comput. Chem. Eng. 2008, 32(11), 2664-2683.

(17) Aronofsky, J.S; Dutton, J.M; Tayyabkhan, M.T. Managerial Planning with Linear Programming. New York: Wiley \& Sons, 1978.

(18) Geddes, R. L. A General Index of Fractional Distillation Power for Hydrocarbon Mixtures. AIChE J. 1958, 4, 389-392.

(19) Jakob, R. R. Estimate number of crude trays. Hydrocarbon Process. 1971, 50, $149-152$.

(20) Raman, R.; Grossmann, I. E. Modelling and computational techniques for logic based integer programming. Comput. Chem. Eng. 1994, 18, 563-578.

(21) Lima, R. M.; Grossmann, I. E.; Jiao, Y. Long-term scheduling of a single-unit multi-product continuous process to manufacture high performance glass. Comput. Chem. Eng., 2011, 35(3), 554-574.

(22) Kopanos, G. M.; Puigjaner, L.; Maravelias, C. T. Production Planning and Scheduling of Parallel Continuous Processes with Product Families. In Ind. Eng. Chem. Res., 2011, 50 (3), 1369-1378

(23) Strategic Petroleum Reserve Crude Oil Assay Manual, 3rd ed.; US Department of Energy (DoE): Washington, DC, 2008.

(24) Riazi, M. R. Characterization and Properties of Petroleum Fractions, 1st ed.; ASTM: West Conshohocken, PA, 2005. 


\section{Appendix A Data For the Example Problems}

Table A-1 Example 1 Transition time in hours

\begin{tabular}{|l|r|r|r|r|r|r|r|r|}
\hline cr & CRUDE1 & \multicolumn{1}{l|}{ CRUDE2 } & CRUDE3 & CRUDE4 & CRUDE5 & CRUDE6 & CRUDE7 & CRUDE8 \\
\hline CRUDE1 & 0 & 5 & 8 & 10 & 15 & 10 & 15 & 5 \\
\hline CRUDE2 & 10 & 0 & 12 & 20 & 22 & 20 & 22 & 10 \\
\hline CRUDE3 & 4 & 6 & 0 & 12 & 16 & 12 & 16 & 20 \\
\hline CRUDE4 & 15 & 20 & 10 & 0 & 12 & 13 & 8 & 9 \\
\hline CRUDE5 & 3 & 8 & 9 & 17 & 0 & 20 & 17 & 8 \\
\hline CRUDE6 & 8 & 10 & 15 & 9 & 13 & 0 & 12 & 10 \\
\hline CRUDE7 & 12 & 20 & 22 & 5 & 8 & 10 & 0 & 20 \\
\hline CRUDE8 & 22 & 20 & 22 & 15 & 20 & 10 & 22 & 0 \\
\hline
\end{tabular}

Table A-2 Example 1 Transition cost

\begin{tabular}{|l|r|r|r|r|r|r|r|r|}
\hline cr & \multicolumn{1}{|c|}{ CRUDE1 } & \multicolumn{1}{c|}{ CRUDE2 } & CRUDE3 & CRUDE4 & CRUDE5 & CRUDE6 & CRUDE7 & CRUDE8 \\
\hline CRUDE1 & 0 & 100 & 160 & 200 & 300 & 240 & 40 & 180 \\
\hline CRUDE2 & 200 & 0 & 240 & 400 & 200 & 400 & 128 & 240 \\
\hline CRUDE3 & 80 & 120 & 0 & 240 & 320 & 160 & 156 & 400 \\
\hline CRUDE4 & 300 & 400 & 200 & 0 & 240 & 60 & 240 & 160 \\
\hline CRUDE5 & 60 & 160 & 180 & 340 & 0 & 100 & 400 & 60 \\
\hline CRUDE6 & 180 & 60 & 240 & 100 & 20 & 0 & 60 & 100 \\
\hline CRUDE7 & 240 & 100 & 20 & 60 & 160 & 180 & 0 & 240 \\
\hline CRUDE8 & 120 & 160 & 200 & 300 & 40 & 300 & 188 & 0 \\
\hline
\end{tabular}

Table A-3 Product demands

\begin{tabular}{|l|l|r|r|r|r|r|r|}
\hline Product & Limit type & week1 & week2 & week3 & week4 & week5 & week6 \\
\hline RG & Minimum & 10 & 35 & 10 & 12 & 35 & 12 \\
\hline PG & Maximum & 20 & 80 & 40 & 17 & 40 & 80 \\
\hline
\end{tabular}

Table A-4 Crude oil availability applied to each time period

\begin{tabular}{|l|l|r|}
\hline & Maximum & Minimum \\
\hline All crude oils & 200 & 10 \\
\hline
\end{tabular}

Table A-5 Crude oil prices (\$/bbl) for all time periods

\begin{tabular}{|l|l|}
\hline crude & Price \\
\hline CRUDE1 & 75 \\
\hline CRUDE2 & 65 \\
\hline CRUDE3 & 75 \\
\hline CRUDE4 & 65 \\
\hline CRUDE5 & 75 \\
\hline
\end{tabular}




\begin{tabular}{|l|l|}
\hline CRUDE6 & 65 \\
\hline CRUDE7 & 75 \\
\hline CRUDE8 & 65 \\
\hline
\end{tabular}

Table A-6 Unit capacities (1000's BPD)

\begin{tabular}{|l|r|}
\hline unit & Maximum \\
\hline CDU & 100 \\
\hline Cat Ref & 20 \\
\hline Cat Crack & 30 \\
\hline
\end{tabular}

Table A-7 Example 1 Additional Information (\$/bbl)

\begin{tabular}{|l|r|}
\hline Data & Value \\
\hline Inventory Cost & 0.00306 \\
\hline CDU Operating Cost & 5 \\
\hline Reformer Operating cost & 7.5 \\
\hline Catalytic Cracker Operating Cost - Light distillate feed & 40 \\
\hline Catalytic Cracker Operating Cost - Gas oil feed & 4 \\
\hline Hydrotreater Operating Cost & 5 \\
\hline
\end{tabular}

Table A-8 Summary of crude oil assays ${ }^{23}$

\begin{tabular}{|c|c|c|c|c|}
\hline Crude oil & API & SG & $\begin{array}{l}\text { LV\% } \\
\text { Distilled }\end{array}$ & TBP (K) \\
\hline \multirow{9}{*}{ Crude1 } & \multirow{9}{*}{37} & \multirow{9}{*}{0.8398} & 0 & 258.4 \\
\hline & & & 5 & 315.7 \\
\hline & & & 10 & 345.7 \\
\hline & & & 30 & 445.1 \\
\hline & & & 50 & 548.2 \\
\hline & & & 70 & 669.4 \\
\hline & & & 90 & 836.1 \\
\hline & & & 95 & 910.3 \\
\hline & & & 100 & 984.9 \\
\hline \multirow{9}{*}{ Crude2 } & \multirow{9}{*}{33.1} & \multirow{9}{*}{0.8597} & 0 & 266.3 \\
\hline & & & 5 & 327.4 \\
\hline & & & 10 & 359.9 \\
\hline & & & 30 & 465.8 \\
\hline & & & 50 & 576.4 \\
\hline & & & 70 & 712.2 \\
\hline & & & 90 & 899.2 \\
\hline & & & 95 & 988.8 \\
\hline & & & 100 & 1078.4 \\
\hline \multirow{2}{*}{ Crude3 } & \multirow{2}{*}{36.4} & \multirow{2}{*}{0.8428} & 0 & 263.7 \\
\hline & & & 5 & 321.4 \\
\hline
\end{tabular}




\begin{tabular}{|c|c|c|c|c|}
\hline & & & 10 & 351.4 \\
\hline & & & 30 & 455.1 \\
\hline & & & 50 & 559.4 \\
\hline & & & 70 & 686.1 \\
\hline & & & 90 & 853.4 \\
\hline & & & 95 & 930.4 \\
\hline & & & 100 & 1007.3 \\
\hline \multirow{9}{*}{ Crude4 } & \multirow{9}{*}{33.2} & \multirow{9}{*}{0.8591} & 0 & 269.9 \\
\hline & & & 5 & 330.5 \\
\hline & & & 10 & 362.9 \\
\hline & & & 30 & 466.3 \\
\hline & & & 50 & 574.4 \\
\hline & & & 70 & 705.4 \\
\hline & & & 90 & 888.3 \\
\hline & & & 95 & 975.4 \\
\hline & & & 100 & 1062.6 \\
\hline \multirow{9}{*}{ Crude5 } & \multirow{9}{*}{35.4} & \multirow{9}{*}{0.8478} & 0 & 267.7 \\
\hline & & & 5 & 324.1 \\
\hline & & & 10 & 353.1 \\
\hline & & & 30 & 450.9 \\
\hline & & & 50 & 554.5 \\
\hline & & & 70 & 671.6 \\
\hline & & & 90 & 847.1 \\
\hline & & & 95 & 926.3 \\
\hline & & & 100 & 1005.5 \\
\hline \multirow{9}{*}{ Crude6 } & \multirow{9}{*}{30.8} & \multirow{9}{*}{0.8718} & 0 & 296.3 \\
\hline & & & 5 & 349.7 \\
\hline & & & 10 & 377 \\
\hline & & & 30 & 486.4 \\
\hline & & & 50 & 596.6 \\
\hline & & & 70 & 734 \\
\hline & & & 90 & 913.6 \\
\hline & & & 95 & 999.6 \\
\hline & & & 100 & 1085.5 \\
\hline \multirow{7}{*}{ Crude7 } & \multirow{7}{*}{34.6} & \multirow{7}{*}{0.8519} & 0 & 264.5 \\
\hline & & & 5 & 327.9 \\
\hline & & & 10 & 362.3 \\
\hline & & & 30 & 477.6 \\
\hline & & & 50 & 583 \\
\hline & & & 70 & 697.4 \\
\hline & & & 90 & 855.2 \\
\hline
\end{tabular}




\begin{tabular}{|c|c|c|c|c|}
\hline & & & 95 & 928.7 \\
\hline & & & 100 & 1002.2 \\
\hline \multirow{9}{*}{ Crude8 } & \multirow{9}{*}{32.4} & \multirow{9}{*}{0.8633} & 0 & 271.5 \\
\hline & & & 5 & 332.9 \\
\hline & & & 10 & 366.3 \\
\hline & & & 30 & 472.7 \\
\hline & & & 50 & 579.3 \\
\hline & & & 70 & 717.5 \\
\hline & & & 90 & 905.2 \\
\hline & & & 95 & 995.2 \\
\hline & & & 100 & 1085.2 \\
\hline
\end{tabular}

Table A-9 Refinery Product Prices $(\$ / \mathbf{b b l})$ for time periods

\begin{tabular}{|l|l|}
\hline Product & Price \\
\hline FG & 35 \\
\hline$P G$ & 135 \\
\hline$R G$ & 121 \\
\hline Dist & 87 \\
\hline FO & 76.5 \\
\hline
\end{tabular}

